\title{
ВЫЯВЛЕНИЕ СОВРЕМЕННЫХ ТЕНДЕНЦИЙ И ОСНОВНЫХ ПРОБЛЕМ В ОРГАНИЗАЦИИ ДЕЯТЕЛЬНОСТИ СОВЕТА ДИРЕКТОРОВ В РОССИЙСКИХ И ЗАРУБЕЖНЫХ КОМПАНИЯХ
}

\section{IDENTIFICATION OF MODERN \\ TRENDS AND MAIN PROBLEMS \\ IN THE ORGANIZATION OF THE BOARD \\ OF DIRECTORS IN RUSSIAN AND FOREIGN COMPANIES}

V. Zhukov

I. Okhotnikov

I. Sibirko

Summary. Today, the activities of joint-stock companies have become widespread and remain attractive to entrepreneurs based on favorable conditions for conducting economic activities. However, the problem of the need to assess the type of corporate governance in joint-stock companies, the definition of effective models of corporate control to ensure profitable activities as well as their implementation remains unresolved. The article shows the actualization of the institute of independent directors in Russian joint-stock companies compared to global trends. The problem of the lack of a system of independent directors is revealed and the prospects of the study are shown.

Keywords: joint-stock company, joint-stock company management system, independent directors, board of directors, corporate governance.
Жуков Владислав Борисович

Аспирант, Российская академия народного хозяйства и государственной службы при президенте

Российской Федерации

zhukov.vladislav20@gmail.com

Охотников Илья Викторович

К.э.н., доцент, Российский университет транспорта

(МИИТ)

Сибирко Иван Владимирович

К.э.н., доцент, Российский университет транспорта

(МИИТ)

Аннотация. На сегодняшний день деятельность акционерных обществ приобрела широкое распространение, и они по-прежнему остаются привлекательными для предпринимателей исходя из благоприятных условий ведения хозяйственной деятельности. Однако, нерешенной остается проблема необходимости оценки типа корпоративного управления в акционерных обществах, определение эффективных моделей корпоративного контроля для обеспечения прибыльной деятельности, а так же их имплементация. В статье показана актуализация института независимых директоров в российских акционерных обществах в сравнении с мировыми тенденциями. 0бнаружена проблема отсутствия системы независимых директоров и показаны перспективы исследования.

Ключевые слова: акционерное общество, система управления акционерным обществом, независимые директора, совет директоров, корпоративное управление.

нако, на практике в подавляющем большинстве российских публичных компаний советы директоров играют гораздо меньшую роль в процессе управления. На самом деле реальная власть принадлежит контролирующим акционерам и менеджменту (зачастую это одни и те же люди), а советы директоров играют в основном второстепенную роль, рассматривая и официально утверждая планы деятельности компании и результаты их реализации. Такая ситуация характерна для большинства стран с развивающимися рынками $[1 ; 8]$.

Несоответствие официальных полномочий органов управления их реальной деятельности всегда создает серьезные риски и снижает эффективность управления. Хотя, чтобы устранить или хотя бы уменьшить этот пробел, необходимо разобраться в причинах этого несоответствия, и причины его устойчивости. Можно справедливо заявить, что неправильное понимание этих причин 
приводит к неправильным методам их устранения и часто служит только для обострения проблемы.

На сегодня деятельность акционерных обществ приобрела широкое распространение и остаются привлекательными для предпринимателей исходя из благоприятных условий ведения хозяйственной деятельности [2]. Однако, нерешенной остается проблема необходимости урегулирования отношений корпоративного контроля в акционерных обществах, определение эффективных моделей корпоративного контроля для обеспечения прибыльной деятельности.

\section{Степень изученности проблемы}

Проблематика корпоративного управления в зарубежных странах рассматривалась Г. Акоффом, М. Аоки, Ч. Бернардом, П. Друкером, К. Ейзенхардом, Г. Минцбергом, М. Хаммером и др. Каждый из названных ученых согласно направленности своих научных интересов с разной степенью глубины изучает отдельные стороны корпоративного контроля. Однако, исследованию особенностей развития моделей корпоративного контроля в условиях трансформации экономики посвятили свои труды незначительное количество ученых, в частности, отечественные - Ю.Н. Грибова и Т. Долгопятова.

Таким образом, большинство авторов корпоративный контроль рассматривают как функцию управления или подсистему корпоративного управления. Принимая во внимание, что корпоративное управление - это совокупность отношений между отдельными лицами или группами лиц, которые основываются на разделении прав собственности от прав управления (контроля) [19], понятно, что понятие «корпоративного управления» является более широким, чем понятие» корпоративный контроль» и может включать другие контрольные отношения.

Кроме того, следует отметить, что Т.Г. Зайцевой в диссертационном исследовании выделено три подхода к определению сущности корпоративного контроля: акционерный, управленческий и мотивационный. Согласно с акционерным подходом, корпоративный контроль рассматривается только как возможность акционеров участвовать в управлении АО. Управленческий подход сосредоточивается на определении содержания корпоративного контроля как специфической формы осуществления контроля акционеров над действиями нанятого ими профессионального руководства акционерного общества. Определение мотивационной природы корпоративного контроля заключается в установлении взаимозависимости между поведением различных групп участников в корпоративных отношениях [17].
Обобщение выделенных подходов позволило автору определить сущность корпоративного контроля, как гибкой системы обеспечения интересов широкого круга участников корпоративных отношений, что позволяет предупреждать возникновение корпоративных конфликтов путем определения влияния различных групп участников на управленческий процесс и соответствующей организации корпоративного управления в АO [19].

Т.Г.Долгопятова считает, что корпоративный контроль в успешных предприятиях принадлежит администрации или внешним владельцам, а в неуспешных предприятиях - концентрируется у руководителей предприятия либо остается рассеянным [13].

Учитывая рассмотренное выше, считаем, что под моделью корпоративного контроля следует понимать разработанную конструкцию, что отражает эффективное распределение контроля в акционерном обществе между собственниками и менеджерами.

Изучая труды зарубежных ученых [6; 10], установлено, что учеными недостаточно внимания уделено исследованию методов корпоративного контроля. Большинство из ученых исследуют в своих трудах методы корпоративного управления. Однако, как определено выше, корпоративный контроль является подсистемой корпоративного управления, поэтому считаем целесообразным дальнейшее рассмотрение исследуемого вопроса.

В научной литературе стран с трансформационной экономикой рассмотрение проблем, связанных с деятельностью наблюдательных советов акционерных обществ, является довольно новым. Эта тематика, в частности, представлена в разработках И.В. Беликова, В.В. Бобыль, А.Н. Костюка и ряда других исследователей. В трудах упомянутых ученых упор ставится преимущественно на освещении специфики деятельности коллегиальных органов управления компаний корпоративного типа, однако вопросы формирования их персонального состава освещены недостаточно. Этому контексту большее внимание уделяют международные экспертные сообщества и саморегулируемые организации участников фондового рынка [5], ведь привлечение независимых директоров к процессу принятия управленческих решений существенно повышает качество корпоративного менеджмента компаний и способствует обеспечению прозрачности их функционирования. При этом проблемы оценки эффективности для внедрения анализируемого института в этих разработках специально не исследуются, открытыми остаются и вопросы оценки перспективных направлений его применения для обеспечения эффективного влияния государства на структурные сдвиги в корпоративном секторе экономики. 


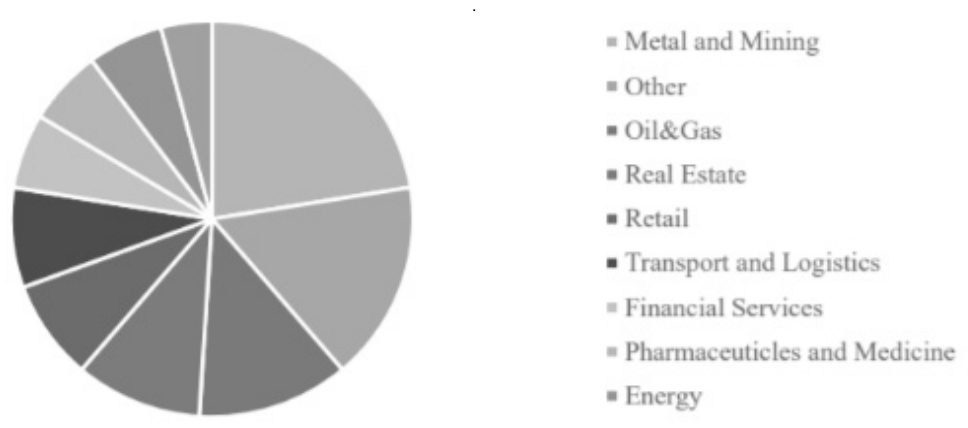

Рис. 1. Наблюдения по секторам экономики Лондонской фондовой биржи
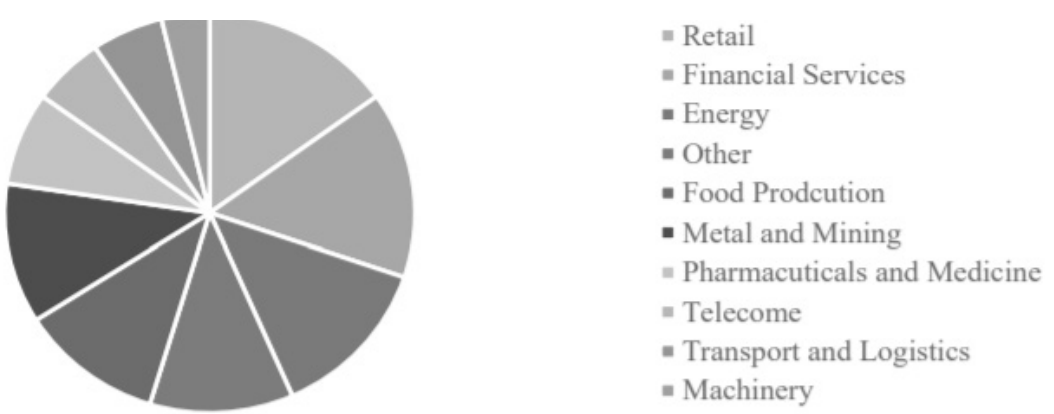

Рис. 2. Наблюдения по секторам, Московская фондовая бирже и РТС

Согласно международной практике, независимый директор является членом совета директоров, не связанным имущественными взаимоотношениями с компанией, в управлении которой он участвует. Это директор, который не зависит ни от одного участника корпоративных отношений, пытается найти баланс интересов всех акционеров и руководствуется в деятельности исключительно личным профессионализмом и соображениями повышения эффективности работы компании в общем. Формально его независимость определяется отсутствием трудовых отношений с компанией, а также связей с ее поставщиками или потребителями. Независимый директор не имеет каких-либо родственных, деловых и других связей, которые влияют или могут влиять на независимость суждения члена совета [8].

Институт независимых директоров призван обеспечить объективный и высокопрофессиональный контроль за деятельностью менеджеров со стороны Совета и эффективное управление компанией в интересах всех ее владельцев. Вопросы деятельности независимых директоров является наиболее актуальным для публичных компаний, акции которых находятся в собственности большого количества мелких акционеров. Такие владельцы, как правило, не способны осуществлять контроль за деятельностью исполнительного органа из-за отсутствия у них полной информации и соответствующих ресурсов. Совет директоров является именно тем механизмом, который призван исправить этот недоста- ток. Для того чтобы Совет мог осуществлять независимый контроль за деятельностью менеджмента и в одинаковой степени представлять интересы всех акционеров (а не определенной их группы), в ее состав должны входить независимые директора [9].

Институт независимых директоров является важной частью современной системы корпоративного управления, уникальным инструментом независимого контроля за деятельностью менеджеров и защиты миноритарных акционеров. Одним из приоритетных направлений законодательных и регулятивных мер, к которым прибегают за рубежом с целью недопущение в будущем корпоративных конфликтов, то есть усиление в совете директоров роли независимых директоров.

\section{Из^ожение основного материала}

Для данного исследования использованы данные 100 российских компаний, вышедших на IPO в период с 2004 по 2019 год. Выборка основывается на данных IPO RBC media. Все компании, представленные в выборке, были разделены на две подвыборки - компании, вышедшие на IPO на Лондонской фондовой бирже или компании, вышедшие на IPO на Московской фондовой бирже/РТС. Компании, которые сделали двойной листинг и вышли на IPO как в России, так и в Великобритании, были распределены по определенной выборке на основе либо размещения акций на соответствующих биржах (если 


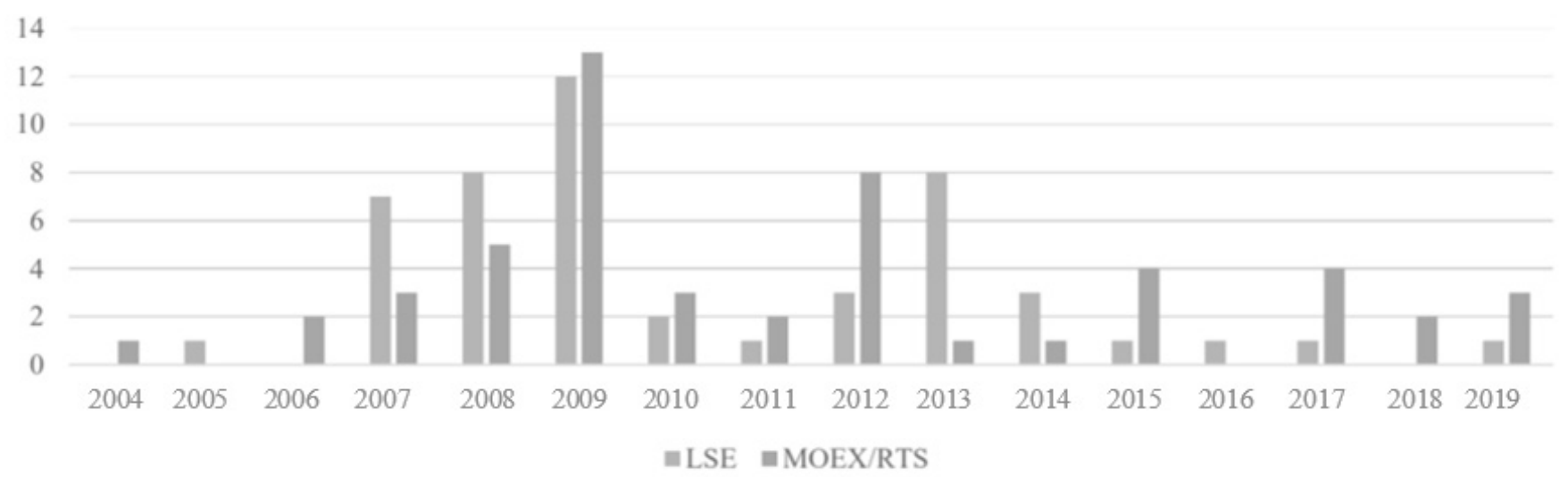

Рис. 3. Количество ІРО в год

эта информация доступна), либо объема торгов в течение первого дня. Некоторые из компании, котирующиеся на MOEX/RTS, были исключены из первоначальной выборки либо из-за отсутствия назначенных директоров в эмиссионных бумагах, либо из-за того, что существовал значительный разрыв между публикацией эмиссионных проспектов и фактическим IPO. Всего существует 48 компаний, отнесенных к Лондонской фондовой бирже, и 52 - к Московской фондовой бирже и РТС.

Список первичных публичных предложений был получен из базы данных Zephyr и дополнительно дважды проверен с помощью базы данных SPARK. Все переменные были собраны вручную из эмиссионных бумаг IPO, проспектов эмиссии, отчетов о результатах размещения и годовых или квартальных отчетов.

Большинство переменных, таких как размер совета директоров, количество иностранных директоров, количество внешних директоров и все контрольные переменные, за исключением рыночной капитализации, извлекаются непосредственно из проспектов компаний или эмиссионных бумаг. В то же время, количество независимых директоров не было четко указано в эмиссионных бумагах, особенно в том, что касается бумаг, выпущенных для российских листингов. Более того, в некоторых случаях директора, названные независимой компанией, имели некоторые связи с фирмой. Эти случаи требовали глубокого анализа, чтобы определить, является ли директор действительно независимым. Для проведения такого исследования мы опирались на кодекс корпоративного поведения в отношении российских рынков капитала, а также на Кодекс корпоративного управления Великобритании для рынков капитала Великобритании. Алгоритм определения независимости директоров основан на исследовании А. Муравьева [14] с некоторыми незначительными изменениями, подходящими для рынков Великобритании.
Как видно из рисунков 1 и 2, различные фондовые биржи привлекают разные компании. Все компании нефтегазового сектора предпочитают размещать свои акции в Великобритании. Кроме того, многие металлургические и горнодобывающие фирмы заинтересовались английскими рынками капитала. Причин этого явления может быть две. Во-первых, влияние одноранговых компаний, котирующихся на определенной фондовой бирже, что привлекает компании из той же отрасли. Во-вторых, нефтяные, газовые и металлургические компании - это, как правило, крупные предприятия, которые стремятся привлечь капитал в значительных объемах и разных формах, включая эмиссию облигаций, и рассматривают международное размещение как лучшую основу для будущего роста капитала.

Если говорить о российских рынках капитала, то здесь больше компаний из финансового, продовольственного и энергетического секторов. Большинство энергетических компаний были созданы в ходе реформирования РАО «ЭС», обслуживают конкретный регион и наблюдается присутствие российского правительства в структуре собственности и совете директоров, что делает эти компании более подходящими для листинга в России. Если говорить о российских продовольственных компаниях, вышедших на IPO внутри страны, то большинство из них относительно невелики и поэтому не соответствуют критериям международных рынков.

Как видно из рисунка 3, количество IPO, размещенных в Лондоне и Москве, достигло своего пика в период с 2007 по 2009 год, когда значительное число крупнейших российских компаний стали публичными. Мировой финансовый кризис может объяснить резкое падение активности на рынках капитала, последовавшее после этого периода. После 2 лет депрессии рынки начали восстанавливаться, но после 2015 года на Лондонской фондовой бирже наблюдалась довольно низкая активность, ограниченная максимум одним листингом в год. Отчасти 
Таблица 1. Описательная статистика правления

\begin{tabular}{|l|l|l|l|l|l|l|l|l|}
\hline \multicolumn{2}{l}{ LSE } & \multicolumn{1}{l|}{ MSEIRTS } \\
\hline Переменная & Средний & Норматив & Минимум & Максимум & Средний & Норматив & Минимум & Максимум \\
\hline Размер выборки & 9 & 2,6 & 5 & 19 & 8 & 3 & 4 & 19 \\
\hline $\begin{array}{l}\text { Неисполнительные } \\
\text { должностные лица }\end{array}$ & 7 & 2,1 & 3 & 11 & 6 & 1,5 & 3 & 13 \\
\hline Руководители & 2 & 2,06 & 0 & 10 & 2 & 1,3 & 0 & 7 \\
\hline $\begin{array}{l}\text { Независимые } \\
\text { директора }\end{array}$ & 3 & 1,3 & 1 & 6 & 2 & 1,5 & 0 & 5 \\
\hline $\begin{array}{l}\text { Иностранные } \\
\text { директора }\end{array}$ & 3 & 1,7 & 0 & 6 & 1 & 1,4 & 0 & 5 \\
\hline
\end{tabular}

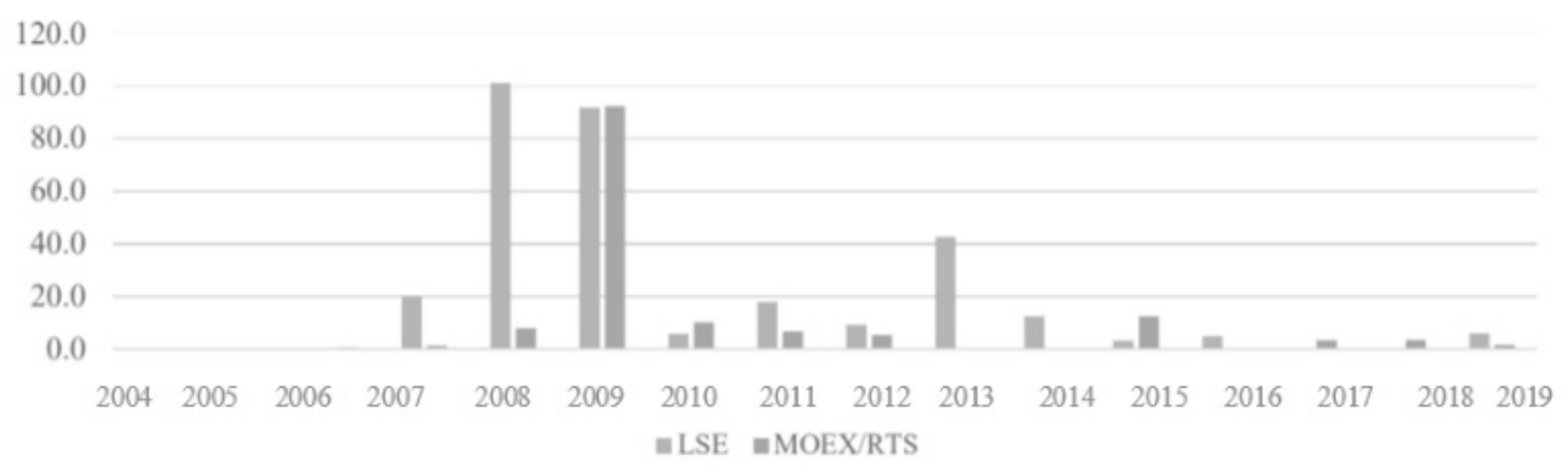

Рис. 4. Общая рыночная капитализация компаний, ежегодно выходивших на рынок (млрд. долл.)

это можно объяснить либо спадом российской экономики, либо дело в том, что большинство нефтяных, газовых, металлургических или горнодобывающих компаний уже выходили на IPO в предыдущие годы. Разница в том, что в последние годы российские компании выходят на биржу почти исключительно на MOEX, в отличие от предыдущих лет.

В таблице 1 можно проследить различия в структуре Советов директоров компаний, котирующихся на разных фондовых рынках. Размер совета директоров в среднем больше для компаний, котирующихся на LSE, что можно объяснить тем фактом, что в среднем компании, котирующиеся на Лондонской бирже, крупнее и имеют более сложную собственность и структуру, которая требует большего количества членов в соответствии с Правилами листинга. Одна из компаний MOEX не соответствует требованиям по минимальной численности совета директоров из 5 человек, а некоторые компании MOEX не сформировали совет директоров до IPO и поэтому были исключены из выборки.

Как и ожидалось, в компаниях, котирующихся на LSE, в среднем больше неисполнительных и независимых ди- ректоров. 5 лондонских компаний имели меньше независимых членов в совете директоров, чем требовалось, в то время как 10 российских компаний вообще не имеют независимых директоров, а 8 имеют меньше необходимого минимума. Важно отметить, что количество заявленных компанией независимых директоров и фактических независимых директоров может отличаться в связи с тем, что для выявления действительно независимого директора использовался алгоритм, основанный на корпоративном кодексе 2002/2012 годов.

Кроме того, неудивительно, что в московских компаниях, котирующихся на бирже, гораздо меньше иностранных директоров. На самом деле в 34 из 52 компаний нет иностранных директоров, в то время как для компаний LSE это справедливо только для 8 фирм из 48.

В таблице 2 представлена описательная статистика по всем переменным (за исключением части независимых и иностранных директоров, эта переменная обсуждалась выше), используемым в регрессионных моделях. Видно, что российские компании в среднем не сильно занижены как на LSE, так и на MOEX со значениями 1,9 и 1, 8 процента соответственно. Однако важно подчер- 
Таблица 2. Описательная статистика переменных

\begin{tabular}{|c|c|c|c|c|c|c|c|c|}
\hline \multirow{2}{*}{ Переменная } & \multicolumn{4}{|l|}{ LSE } & \multicolumn{4}{|c|}{ MOEX/RTS } \\
\hline & Средний & Норматив & Мин. & Макс. & Средний & Норматив & Мин. & Макс. \\
\hline \multicolumn{9}{|l|}{ Зависимая переменная } \\
\hline Занижение цен & 0,019 & 0,11 & $-0,49$ & 0,21 & 0,018 & 0,95 & $-0,28$ & 0,39 \\
\hline \multicolumn{9}{|l|}{ Независимые Переменные } \\
\hline \multicolumn{9}{|l|}{ Переменные, являющиеся частью вектора платы } \\
\hline $\begin{array}{l}\text { Средний срок пребывания директора } \\
\text { в совете директоров }\end{array}$ & 2,41 & 1,35 & 0,6 & 7,27 & 2,89 & 2,05 & 0,6 & 11,24 \\
\hline $\begin{array}{l}\text { Среднее количество директорских } \\
\text { и управленческих должностей } \\
\text { генерального директора и других } \\
\text { руководителей. }\end{array}$ & 2,32 & 2,52 & 0 & 9 & 3 & 3,8 & 0 & 19 \\
\hline $\begin{array}{l}\text { Общее количество внешних директорских } \\
\text { должностей } \\
\text {, занимаемых независимыми директорами } \\
\end{array}$ & 11,5 & 8,39 & 0 & 40 & 7,8 & 8,9 & 0 & 37 \\
\hline $\begin{array}{l}\text { Средний стаж работы соответствующих } \\
\text { директоров. }\end{array}$ & 12,6 & 5 & 4,2 & 29 & 11,5 & 3,4 & 5,2 & 20,1 \\
\hline $\begin{array}{l}\text { Процент акций, принадлежащих } \\
\text { председателю правления и } \\
\text { остальным членам правления }\end{array}$ & 0,27 & 0,32 & 0 & 0,89 & 0,24 & 0,27 & 0 & 0,9 \\
\hline \multicolumn{9}{|c|}{ Переменные, являющиеся частью базового вектора } \\
\hline $\begin{array}{l}\text { Возраст компании, рассчитываемый как } \\
\text { количество } \\
\text { лет между основанием и IPO }\end{array}$ & 10,47 & 5,13 & 21 & 1 & 11,9 & 6,2 & 1 & 24 \\
\hline $\begin{array}{l}\text { Общее количество членов совета } \\
\text { директоров }\end{array}$ & 4378,8 & 9220 & 3 & 52403 & 3652 & 12728 & 2,12 & 89551 \\
\hline $\begin{array}{l}\text { Процентное отношение долга } \\
\text { к собственному капиталу компании }\end{array}$ & 2,03 & 2,07 & 0,01 & 7,29 & 2,38 & 2,24 & 0,12 & 11,2 \\
\hline $\begin{array}{l}\text { ROA (Рентабельность активов, } \\
\text { рассчитываемая как соотношение между } \\
\text { прибылью компании и балансовой } \\
\text { стоимостью активов) }\end{array}$ & 0,048 & 0,16 & 0,3 & $-0,89$ & 0,09 & 0,14 & 0,84 & $-0,01$ \\
\hline
\end{tabular}

кнуть, что стандартное отклонение на LSE значительно ниже, и поэтому результаты IPO компаний в среднем менее волатильны. Некоторые экстремальные значения занижения цен на 39\% и завышение цены на 49\% можно увидеть, но подобные наблюдения довольно редки для данной выборки.

На рис. 5 представлена визуализация занижения IPO с помощью диаграммы. Как видно на графике, после 2015 года отклонений от средних значений стало значительно меньше. Можно предположить, что это связано с характером недавних IPO, которые привлекают меньше внимания и ценятся ниже. Кроме того, интересно, что уровни занижения цен российских компаний очень малы по сравнению с девелоперскими рынками, такими как США (16,2\%), Корея (64,2\%) или Гонконг (21\%).

Указанные обстоятельства обусловливают целесообразность использования института независимых директоров в процессе реализации государственной политики реструктуризации корпоративного сектора. Так, одним из приоритетных направлений принятия таких мер является содействие выходу компаний на международные фондовые рынки. В частности, новые правила листинга на Нью-Йоркской фондовой бирже содержат требование о том, что сверх половины членов Совета публичной компании должны быть независимыми. Кроме того, комитет совета, который назначает внешнего аудитора, должен состоять исключительно из независимых директоров. Компаниям, не отвечающим этим требованиям, будет проблематично получить листинг на бирже, а те, которые его получили ранее, могут быть исключены из листинга [15].

Следует также принять во внимание и то, что реструктуризационные процессы в корпоративном секторе часто сопровождаются обострением конфликтов между различными группами акционеров. Государство, выполняя функции участника компаний, имеет гораздо больше возможностей отстаивать свою позицию, однако нередко это с целью обеспечения ее сугубо краткосрочных интересов. Если в составе наблюдательного совета 


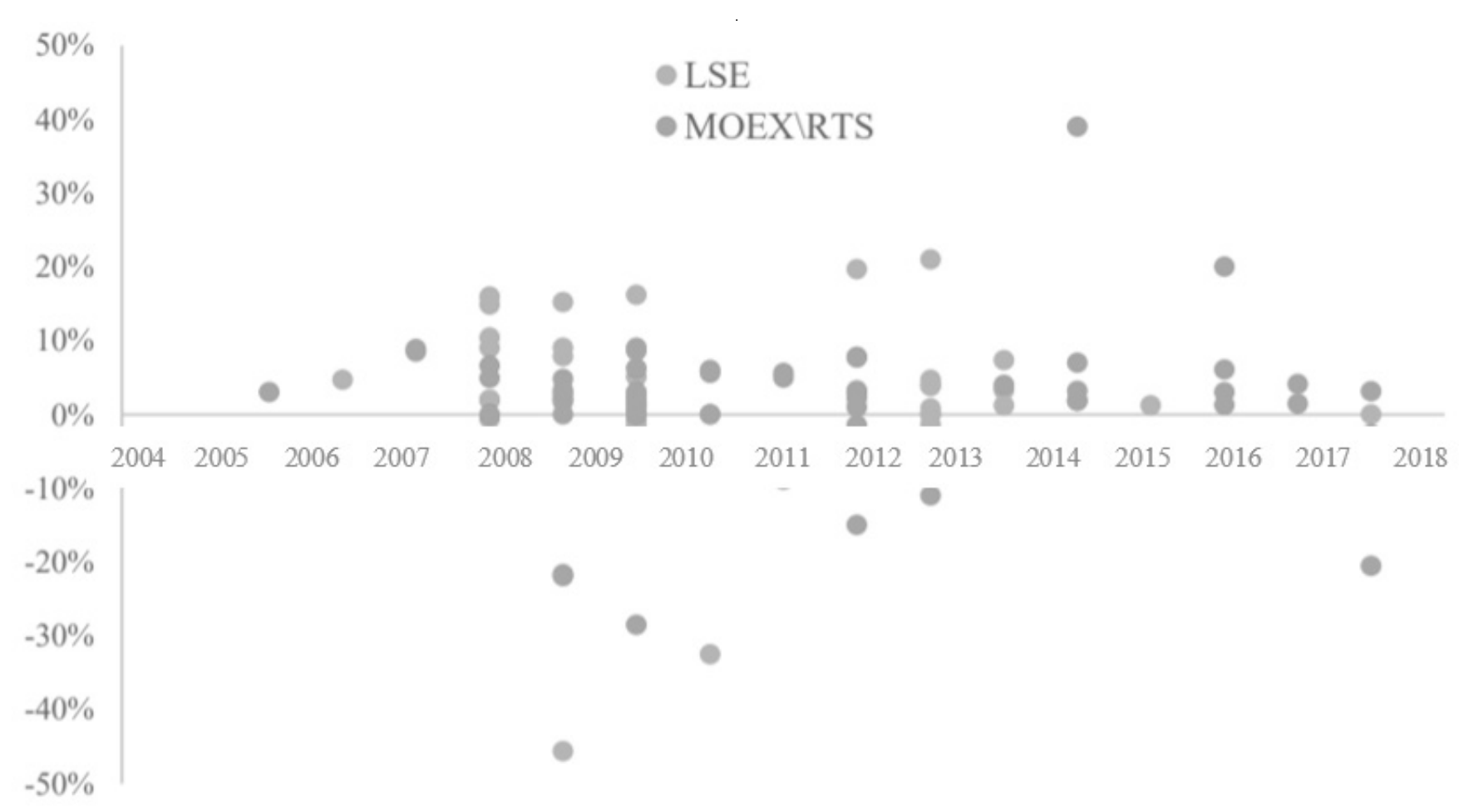

Рис. 5. Ежегодное занижение цен на IPO

появятся независимые директора, то риск доминирование тактических интересов над стратегическими (долгосрочными) целями развития компаний существенно уменьшается. Государство получает стратегические преимущества, поскольку стабильное развитие компании и повышение уровня ее капитализации даст возможность повысить стоимость государственной доли и получить дополнительные дивиденды.

\section{Выво $\triangle ы$}

Таким образом, институт независимых директоров выступает мощным средством обеспечения государственно-управленческого влияния на процессы структурных изменений в корпоративном секторе экономики. Именно независимые директора должны контролировать и отстаивать прозрачность принятия решений, полноту и правильность оплаты налогов, своевременную выплату заработной платы работникам компании, то есть предотвращать угрозы, которые непосредственно влияют на ее финансовое состояние и рыночные позиции.
Эффективность использования указанного института в системе государственного управления реструктуризацией деятельности компаний зависит от развития других (внешних) рамочных условий: корпоративного законодательства, налоговой политики, судебной системы, порядка отчетности и ведения бухгалтерского учета и тому подобное.

Недостаточное развитие института независимых директоров в России, наше мнение, объясняется спецификой развития отечественного корпоративного бизнеса. В нашей стране малым и средним бизнесом в основном управляют его владельцы и их представители (доверенные лица), которые в своих интересах эффективно контролируют исполнительный менеджмент, но еще не настолько «отошли» от управления, чтобы нуждаться в помощи независимых директоров. Пока мажоритарные акционеры (собственники) активно участвуют в управлении и контролируют менеджмент и не нуждаются в этом в помощи, до тех пор у них нет необходимости развивать институт независимых директоров.

\section{ЛИТЕРАТУРА}

1. Berezinets, I.V., Ilina, Y.B., Cherkasskaya A.D (2013). "Structure of board of Directors and Finical performance of Russian 0JSCs". In:. Вестник Санкт-Петербургского университета 2013, 3.

2. Bhatia M., Mehrotra, V. (2016) “Determinants of Intellectual Capital Disclosure: Evidence from Indian Banking Sector”. In: South Asian Journal of Management; New Delhi, 23, pp. 89-111. 
3. Drobetz, W., Beiner, S., Zimmerman, H., and Schmid, F. (2016). "Is board size an independent corporate governance mechanism". In: Kyklos, 57, pp. 327-356.

4. Ernst \& Young (EY). (2016). "EY Global IPO Trends Q1 2016", pp. 1-16. Retrieved from http://www.ey.com/Publication/vwLUAssets/EY_Global_IP0_Trends_ Q4_2013/\$FILE/EYGlobal-IP0-Trends-04-2013.pdf

5. Green, C., Homroy, S. (2018) “'Female Directors, Board Committees and Firm Performance". In: European Economic Review, 102, pp. 19-38

6. Loughran, T., Ritter, J.R., \& Rydqvist, K. (2016). "Initial public offerings: International Insights”. In: Contemporary Finance Digest, 2.1, pp. 165-196

7. Mahatidana, M. (2017). "An Examination Factors Influencing Underpricing of IPOs in Financial and Manufacturing Industries on The Indonesia Stock Exchange over The Period of 2011-2016". In: International Journal of Scientific and Research Publications, 7.11, pp.457-502.

8. Mehorta, S.(2016). "Accentuating role of board for corporate governance in Listed Indian Companies". In: International Journal of Business and General Management, 3.2, pp. 47-56

9. Menozzi A,. Urtiaga M. (2014) “Board composition and performance in State-Owned Enterprises: evidence from the Italian public utilities secto

10. MOEX. (2019)."MOEX guide: How to become public?" Moscow. Retrieved from http://ipoguide.moex.com/index.html

11. MSCI (2019). MSCI RUSSIA INDEX (RUB).

12. Muravyev, A., Berezinets, I., \& llina, Y. (2014). "The structure of corporate boards and private 61 benefits of control: Evidence from the Russian stock exchange”. In: International Review of Financial Analysis, 34, pp. 247-261

13. PriceWaterhouseCoopers (2015). "Survey of Board of Directors of Russian Companies" Retrieved from: https://www.pwc.ru/en/governance-risk-compliance/assets/ rbs_2015.pdf

14. Russian Association of Independent Directors(2020). "Development of institution of independent directors". Retrieved from: http://www.nand.ru/upload/razvitieinstituta-nezavisimixdirectorov-2020.pdf Baker, McKenzie, \& Oxford Economics. GLOBAL TRANSACTIONS: The Impact of Macro Trends

15. Salancik, G., Pfeffer, J.(2017). "Effects of Ownership and Performance on Executive Tenure in U.S. Corporations". In: Academy of Management Journal. 23.4, pp. 653-664.

16. Zhi-Jian Xu, Li Wang, Jing Long, (2017) “The impact of director's heterogeneity on IPO underpricing”. In: Chinese Management Studies,11, pp 102-1.

17. Завертяева М.А., Лопес-Итурриага Ф. Дж. Сети директоров в российских советах директоров: скрытая часть айсберга корпоративного управления // Российский журнал менеджмента. 2020. № 1. URL: https://cyberleninka.ru/article/n/networks-of-directors-on-russian-boards-the-hidden-part-of-the-corporategovernance-iceberg

18. Никулин Е.Д., Свиридов А.А., Смирнов М.В. Взаимосвязь характеристик совета директоров, комитета по аудиту и уровня манипулирования прибылью: анализ российских компаний // Российский журнал менеджмента, vol. 18, no. 2, 2020, pp. 189-216.

19. Складчиков С.В., Залесны Я., Гончаров В.В. Роль корпоративного контроля в организации и деятельности акционерных обществ // Полицейская и следственная деятельность, no. 3, 2020, pp. 20-28.

() Жуков Владислав Борисович ( zhukov.vladislav20@gmail.com ),

Охотников Илья Викторович, Сибирко Иван Владимирович.

Журнал «Современная наука: актуальные проблемы теории и практики»

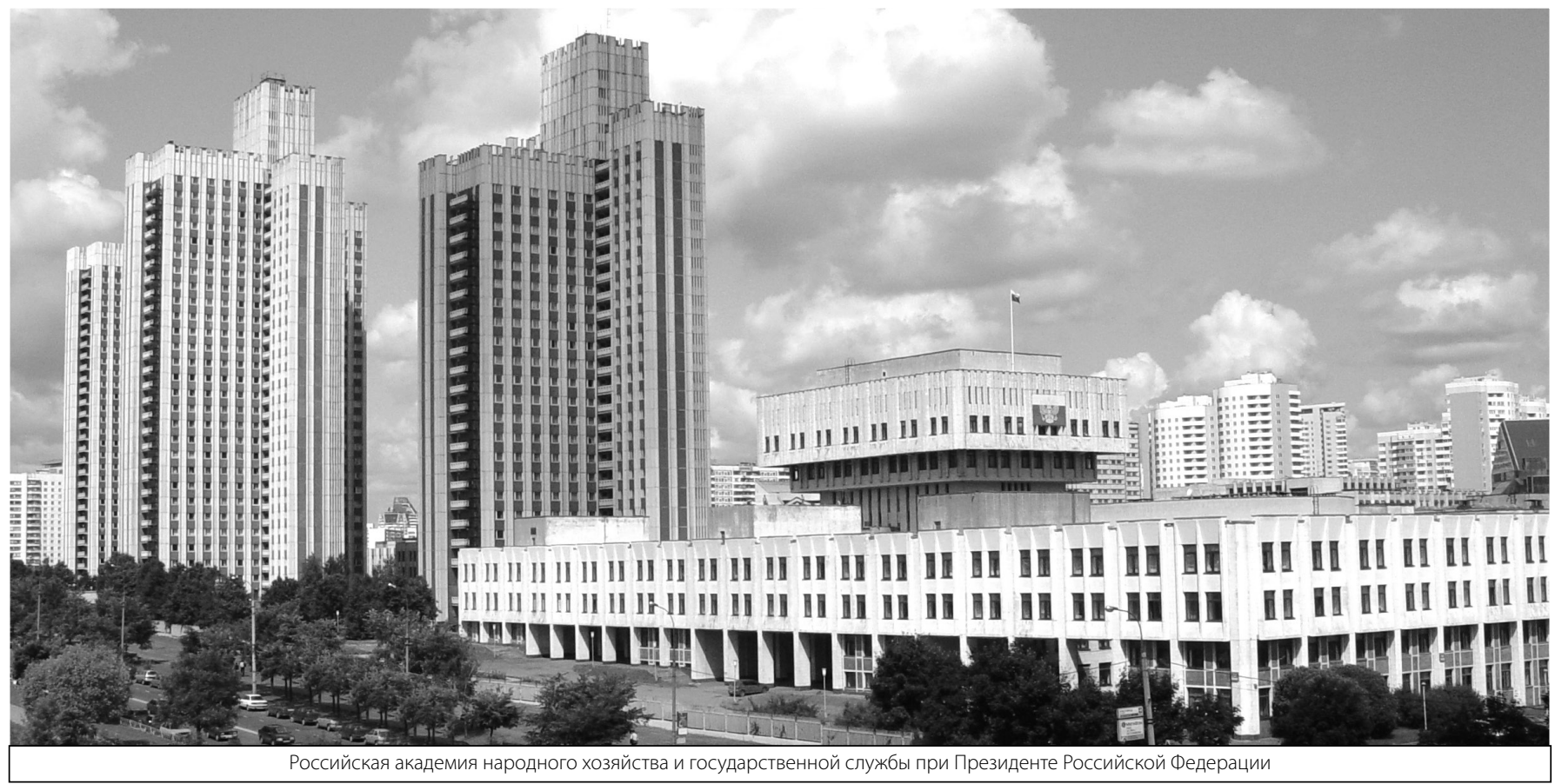

